\title{
Interface and layer periodicity effects on the thermal conductivity of copper-based nanomultilayers with tungsten, tantalum, and tantalum nitride diffusion barriers
}

Cite as: J. Appl. Phys. 128, 195302 (2020); doi: 10.1063/5.0019907

Submitted: 26 June 2020 . Accepted: 9 October 2020 .

Published Online: 19 November 2020

Claudia Cancellieri, ${ }^{7}$ (D) Ethan A. Scott, ${ }^{2}$ (D) Jeffrey Braun, ${ }^{2}$ (D) Sean W. King, ${ }^{3}$ (D) Ron Oviedo, ${ }^{3}$ Christopher Jezewski, ${ }^{3}$ John Richards, ${ }^{3}$ Fabio La Mattina, ${ }^{7}$ (D) Lars P. H. Jeurgens, ${ }^{7}$ (D) and Patrick E. Hopkins ${ }^{2,4,5, a)}$ (iD

\author{
AFFILIATIONS \\ ${ }^{1}$ Empa, Swiss Federal Laboratories for Materials Science and Technology, Überlandstrasse 129, 8600 Dübendorf, Switzerland \\ ${ }^{2}$ Department of Mechanical and Aerospace Engineering, University of Virginia, Charlottesville, Virginia 22904, USA \\ ${ }^{3}$ Logic Technology Development, Intel Corporation, Hillsboro, Oregon 97124, USA \\ ${ }^{4}$ Department of Materials Science and Engineering, University of Virginia, Charlottesville, Virginia 22904, USA \\ ${ }^{5}$ Physics Department, University of Virginia, Charlottesville, Virginia 22904 USA
}

Note: This paper is part of the Special Topic on Photothermics.

a) Author to whom correspondence should be addressed: phopkins@virginia.edu

\begin{abstract}
Nanomultilayers are complex architectures of materials stacked in sequence with layer thicknesses in the nanometer range. Their application in microelectronics is challenged by their thermal stability, conductivity, and interface reactivity, which can compromise their performance and usability. By using different materials as thermal barriers and by changing their thickness, it is possible to manipulate interfacial effects on thermal transport. In this work, we report on the thermal conductivity of $\mathrm{Cu} / \mathrm{W}, \mathrm{Cu} / \mathrm{Ta}$, and $\mathrm{Cu} / \mathrm{TaN}$ sputter deposited nanomultilayers with different thicknesses. The resistive interfacial effects are rationalized and discussed also in relation to the structural transformation into a nano-composite upon high-temperature annealing.
\end{abstract}

Published under license by AIP Publishing. https://doi.org/10.1063/5.0019907

\section{INTRODUCTION}

Nanomultilayers (NMLs) represent an important class of nanomaterials, which find numerous applications in the fields of micro- and nanoelectronic, optical, medical, and sensing devices. These nano-architectures can be made functional, and their mechanical, chemical, and/or physical properties can be tailored through microstructural and interfacial design. Currently, $\mathrm{Cu} / \mathrm{W}, \mathrm{Cu} / \mathrm{Ta}$, and $\mathrm{Cu} / \mathrm{TaN}$ remain among the most ubiquitous multilayers used in interconnect systems, which can be attributed to longstanding fabrication infrastructures, cost considerations, and scalability. ${ }^{1-10}$ Despite the capability of manufacturing smaller period thicknesses, reduced device dimensions give rise to several engineering challenges. For example, NML systems are known to be intrinsically thermodynamically unstable as compared to their respective bulk materials due to the high amount of excess energy contributions arising from internal interfaces (i.e., phase and grain boundaries) and internal residual stresses. ${ }^{11-13}$ Furthermore, the interfaces in these systems strongly affect the thermal properties and yield a reduced thermal conductivity in comparison with the pure constituent bulk materials.

With regard to the influence of interfaces on structural and thermal stability, a number of recent studies have highlighted the advantages and challenges associated with copper-based NMLs. For example, Xue et al. ${ }^{14}$ investigate the role of period thicknesses on the thermal stability of $\mathrm{Cu} / \mathrm{W}$ NMLs, demonstrating a reduction in mechanical integrity among the thinnest periods. Correspondingly, Dong et al..$^{15}$ have reported a significant reduction in the thermal conductivity of $\mathrm{Cu} / \mathrm{W}$ multilayer scaling with period thicknesses, which is largely attributed to a reduction of interface coherence. 
In other copper-based multilayers, including $\mathrm{Cu} / \mathrm{Ta}$, Powers et al. ${ }^{16}$ have demonstrated that hillock formation at elevated temperatures can exacerbate the issue of loss of interface coherence.

For layer thicknesses on the order of carrier mean free paths, interface resistance becomes a critical impediment to heat transfer. ${ }^{17,18}$ In the case of NMLs consisting of constituent layers of different materials or phases, this can arise from the combination of poor mechanical or chemical adherence at the interface and a thermal expansion mismatch between the constituent layers, inhibiting the transfer of vibrational energy across the interface. While lowering effective thermal conductivity by adding interfaces is advantageous for thermoelectric and thermal barrier coating applications, it is undesirable for microelectronic applications where there is a need to dissipate ever increasing amounts of waste heat. Moreover, the thermal resistance of interfaces degrades the performance of materials intended for thermal management, such as polycrystalline diamonds ${ }^{19}$ and nanoscale composites. ${ }^{20}$ It is then clear that a tradeoff should be sought among different combinations of metallic and barrier materials depending on the final application.

In this work, we report a systematic comparison between the thermal conductivity of Cu-based nanomultilayers with different barrier layers: Ta, TaN, and W. For select films, the thermal boundary conductance (TBC) is derived through a series resistance model and is discussed in relation to the interface density and layer thickness. For further insight into microstructural effects on thermal transport within the NMLs, samples are additionally annealed until the point of layer diffusion. At sufficiently high temperatures, the NMLs composed of alternating metallic and barrier layers are found to degrade into nanocomposites (NCs). Starting from a NML structure of alternating, immiscible metals, the hightemperature thermal degradation of the NML proceeds by thermal grooving of grain boundaries, pinching-off of the nanolayers and subsequent spheroidization of residual layer-fragments, leading to a NC formation. ${ }^{21-24}$ The NML to NC transformation is accompanied by complete stress relaxation in both layers. ${ }^{22,23}$

The results of this study provide useful insights for a number of engineering disciplines as understanding of thermal transport in nano-sized features is critical for next generation device functionality including multilayered structures. Furthermore, while a majority of works investigating the effects of interfacial resistances on thermal transport have focused upon non-metal/non-metal or metal/non-metal interfaces, considerably fewer works report on $\mathrm{metal} / \mathrm{metal}$ interfaces in which thermal transport is electron dominated and Kaptiza conductances are much higher. ${ }^{25-28}$

\section{EXPERIMENTAL PROCEDURE}

\section{A. Material deposition}

The $\mathrm{Cu} / \mathrm{Ta}$ and $\mathrm{Cu} / \mathrm{TaN}$ multilayers were deposited on $300 \mathrm{~mm}$ diameter Si (001) substrates using an industry standard physical vapor deposition (PVD) tool. ${ }^{29}$ Prior to $\mathrm{Cu} / \mathrm{Ta}(\mathrm{N})$ multilayer formation, a $100 \mathrm{~nm}$ thick thermal oxide was grown on the $\mathrm{Si}$ (001) substrate followed by plasma enhanced chemical vapor deposition (PECVD) of $100 \mathrm{~nm}$ thick SiN and $25 \mathrm{~nm}$ thick PVD Ta(N) adhesion layers. A nominally $400 \mathrm{~nm} \mathrm{Cu}$ buffer layer was subsequently deposited by combined PVD and electroplating methods followed by a chemical mechanical polish to planarize and reduce


FIG. 1. Representative schematic of the layer contents, with a nominal thickness, is displayed in (a) and (b) for the $\mathrm{Cu} / \mathrm{Ta}(\mathrm{N})$ and $\mathrm{Cu} / \mathrm{W}$ NML systems, respectively.

the $\mathrm{Cu}$ layer to a final layer thickness of $300 \mathrm{~nm}$. The $\mathrm{Cu} / \mathrm{Ta}(\mathrm{N})$ multilayers were subsequently deposited on the $300 \mathrm{~nm} \mathrm{Cu}$ by PVD with period thicknesses ranging from 5 to $40 \mathrm{~nm}$. The $\mathrm{Cu} / \mathrm{Ta}(\mathrm{N})$ layers were fabricated on the $300 \mathrm{~nm}$ thick $\mathrm{Cu}$ layer to mimic the use of $\mathrm{Ta}$ and $\mathrm{TaN}$ as diffusion barriers in microelectronic $\mathrm{Cu}$ metal interconnects. $\mathrm{Cu} / \mathrm{W}$ NMLs were deposited on $2^{\prime \prime}$ $\alpha-\mathrm{Al}_{2} \mathrm{O}_{3}$ single-crystalline substrates, sapphire-C (0001), by DC unbalanced magnetron sputtering in a high vacuum chamber (base pressure $<10^{-8}$ mbar) from two $2^{\prime \prime}$ targets of pure W (99.95\%) and $\mathrm{Cu}(99.99 \%)$ confocally arranged and operated at $200 \mathrm{~W}$. Before insertion in the deposition apparatus, the sapphire substrates were ultrasonically cleaned using acetone and ethanol. Prior to deposition, possible surface contamination on the $\alpha-\mathrm{Al}_{2} \mathrm{O}_{3}$ substrates (mostly adventitious carbon) was removed by $\mathrm{Ar}^{+}$sputter cleaning for $5 \mathrm{~min}$ applying a RF bias of $100 \mathrm{~V}$. First, a $25 \mathrm{~nm}$-thick W buffer layer was deposited on the sputter-cleaned substrate. Next, 100 repetitions of alternating $\mathrm{Cu}$ and $\mathrm{W}$ layers with different (nominal) thicknesses of 5, 3, and $10 \mathrm{~nm}$ were deposited on top. For the heat treatment, select as-prepared samples were isothermically annealed ex situ at temperatures ranging from 500 to $800^{\circ} \mathrm{C}$ for $100 \mathrm{~min}$ in vacuum $\left(<10^{-5} \mathrm{mbar}\right) .^{21,23}$ For clarity of sample structures, a schematic of each NML system is shown in Fig. 1. For further details on individual samples, we refer the reader to Table S3 of the supplementary material.

\section{B. Characterization}

A Bruker D8 Discover x-ray diffractometer, operated in the Bragg-Brentano geometry, was used to measure 2-theta $(2 \theta)$ scans for the as-deposited and annealed samples. To access the texture, pole figures of the $\mathrm{Cu}\{111\}$ and $\mathrm{Ta} / \mathrm{TaN}\{110\}$ family of planes were recorded in a point focus geometry. XRD scans and texture measurements were measured at room temperature on ex situ annealed samples.

For thermal property characterization, the samples were coated with an $80 \mathrm{~nm}$ film of $\mathrm{Al}$ to serve as a transducer for time domain thermoreflectance (TDTR). In short, TDTR is a noncontact optical pump probe technique that is used to monitor the change in reflectance of a sample surface in response to a modulated heating event. The output of an ultrafast pulsed laser is split into a pump and probe path: the pump path is modulated at a particular frequency, ultimately inducing the modulated heating event 
TABLE I. Thickness $(d)$, thermal conductivity $(\kappa)$, and volumetric heat capacity $\left(C_{v}\right)$ values used in the thermal model of the TDTR data. The thermal conductivity of the multilayer region as well as the thermal boundary conductance were used as fitting parameters within the model. Thermal properties of the other layers within the system are taken from the literature and referenced accordingly.

\begin{tabular}{|c|c|c|c|c|c|}
\hline System & Layer & Material & $d(\mathrm{~nm})$ & $C_{v}\left(\mathrm{MJ} \mathrm{m}^{-3} \mathrm{~K}^{-1}\right)$ & $\kappa\left(\mathrm{W} \mathrm{m}^{-1} \mathrm{~K}^{-1}\right)$ \\
\hline \multicolumn{6}{|c|}{$\mathrm{Cu} / \mathrm{Ta}(\mathrm{N})$} \\
\hline & 1 & $\mathrm{Al}$ & 80 & $2.43^{34-36}$ & $135^{36,37}$ \\
\hline & 2 & $\mathrm{Cu} / \mathrm{Ta}(\mathrm{N})$ & $110-238$ & $2.89-3.13$ & Fig. 5 \\
\hline & 3 & $\mathrm{Cu}$ & $268-304$ & $3.45^{38}$ & $398^{39,40}$ \\
\hline & 4 & $\mathrm{TaN}$ & $22-31$ & $2.18^{41}$ & $3^{42}$ \\
\hline & 5 & $\mathrm{SiN}$ & 100 & $2.1^{43,44}$ & $2.1^{45}$ \\
\hline & 6 & $\mathrm{SiO}_{2}$ & 100 & $1.65^{36,44}$ & $1.35^{36}$ \\
\hline & 7 & $\mathrm{Si}$ & Bulk & $1.65^{36}$ & $140^{46}$ \\
\hline \multicolumn{6}{|l|}{$\mathrm{Cu} / \mathrm{W}$} \\
\hline & 1 & $\mathrm{Al}$ & 80 & $2.43^{34-36}$ & $135^{36,37}$ \\
\hline & 2 & $\mathrm{Cu} / \mathrm{W}$ & $600-1500$ & $3.02-3.25$ & Fig. 5 \\
\hline & 3 & W & 25 & $2.56^{47}$ & $52.2^{48}$ \\
\hline & 4 & $\mathrm{Al}_{2} \mathrm{O}_{3}$ & Bulk & $3.02^{34}$ & $35^{46}$ \\
\hline
\end{tabular}

at the coated sample surface. The probe path is concentrically focused onto the sample surface with the pump, and the impingement upon the sample surface of the pulsed probe can be delayed relative to that of the pump via a mechanical delay stage, enabling a high temporal resolution. For our measurements, we utilize a Ti: sapphire laser with a repetition rate of $80 \mathrm{MHz}$ with a central wavelength of $800 \mathrm{~nm}$ and a bandwidth of $11 \mathrm{~nm}$. The pump path is frequency doubled to $400 \mathrm{~nm}$ with a bismuth triborate (BIBO) crystal and modulated at $10 \mathrm{MHz}$ using an electro-optic modulator.

The modulated response of the reflected probe is monitored with a lock-in amplifier as a function of delay time. As the measured change in reflectance is proportional to the change in temperature of the surface, the reflectivity decay as a function of time can be fit with a thermal model, ${ }^{30-33}$ with the parameters of interest used as fitting parameters in the model (typically thermal conductivity, $\kappa$, or thermal boundary conductance, $G$ ). As there are numerous layers within the system and because we are interested in the overall thermal conductivity of the multilayer region, we treat the multilayer region as a single continuum within the sample stack. The dimensions of the sample stacks are determined through cross-sectional scanning electron microscopy (XSEM). For the $\mathrm{Cu} / \mathrm{Ta}$ and $\mathrm{Cu} / \mathrm{TaN}$ samples, the sample stack is considered a sevenlayer model comprising an $80 \mathrm{~nm}$ Al capping layer, a $100-250 \mathrm{~nm}$ multilayer region, a $300 \mathrm{~nm}$ copper buffer layer, a $25 \mathrm{~nm} \mathrm{Ta}(\mathrm{N})$ adhesion layer, a $100 \mathrm{~nm} \mathrm{SiN}$ adhesion layer, and a $100 \mathrm{~nm} \mathrm{SiO}$ oxide layer all atop a silicon substrate. The $\mathrm{Cu} / \mathrm{W}$ samples, fabricated upon $\mathrm{Al}_{2} \mathrm{O}_{3}$ substrates, are represented by a four-layer model: an $\mathrm{Al}$ capping layer, the multilayer region, and a $\mathrm{W}$ buffer layer atop the $\mathrm{Al}_{2} \mathrm{O}_{3}$ substrates. The thickness of the $\mathrm{Cu}$ buffer layers as well as the $\mathrm{Ta}(\mathrm{N})$ buffer layers are determined from XSEM measurements. Beneath the $\mathrm{Ta}(\mathrm{N})$, there is reduced sensitivity to a particular layer thickness (see Fig. S6 in the supplementary material), and the nominal thicknesses of the $\mathrm{Si}_{3} \mathrm{~N}_{4}$ and $\mathrm{SiO}_{2}$ layers are utilized. The heat capacity of the multilayer region is calculated by applying a rule of mixtures formulation with the heat capacity values of the constituent layers. The heat capacity and thermal conductivity of the other films are assumed from the literature; particular parameters for each layer in the thermal model are outlined in Table I.

The thermoreflectance data for these NMLs is analyzed in the same method as Cheaito et al., ${ }^{25}$ who previously analyzed $\mathrm{Cu} / \mathrm{Nb}$ multilayers, by treating the thermal conductivity of the multilayer region and the interface between the $\mathrm{Al}$ transducer and the multilayer region as fitting parameters in the thermal model and neglecting the interface resistances for layers underneath the multilayer region. We verify our sensitivity to the thermal resistance of each layer by performing sensitivity analyses in the method of Gundrum et $a l^{26}$ and find that the measurements are most sensitive to the thermal conductivity of the multilayer region, as it is the most thermally resistive region within the sample. Sensitivity analyses as a function of both delay time and modulation frequency are provided in Fig. S6 and S7 of the supplementary material.

\section{RESULTS AND DISCUSSION}

\section{A. Microstructure}

The microstructure of the as-deposited and annealed NMLs was investigated by SEM analysis; micrographs of the as-deposited and $800^{\circ} \mathrm{C}$ heat-treated NML are shown in Fig. 2 (both in plan and cross-sectional views). The surface of the as-deposited NMLs demonstrates uniformity and exhibits a grain-like morphology (as originating from the waviness of the deposited nanolayers; see Ref. 21) with no evidence of cracks, voids, and/or delaminations [Figs. 2(a) and 2(e)]. The average surface roughness $\left(\mathrm{R}_{a}\right)$ derived by AFM (see the supplementary material) is always equal or less than $2 \mathrm{~nm}$, indicating a smooth flat surface. In a cross-sectional view, the $300 \mathrm{~nm}$ thick $\mathrm{Cu}$ bottom layer and the periodicity of the alternating $\mathrm{Cu} / \mathrm{Ta}$ and TaN layers is clearly resolved [Figs. 2(b) and 2(f)], with the deposited nanolayers maintaining relative uniformity across the entire thickness. After annealing at $800^{\circ} \mathrm{C}$, the surface morphology changes drastically [Figs. 2(c) and 2(g)]. The $\mathrm{R}_{a}$ is now around $70-80 \mathrm{~nm}$ [see the supplementary material], 

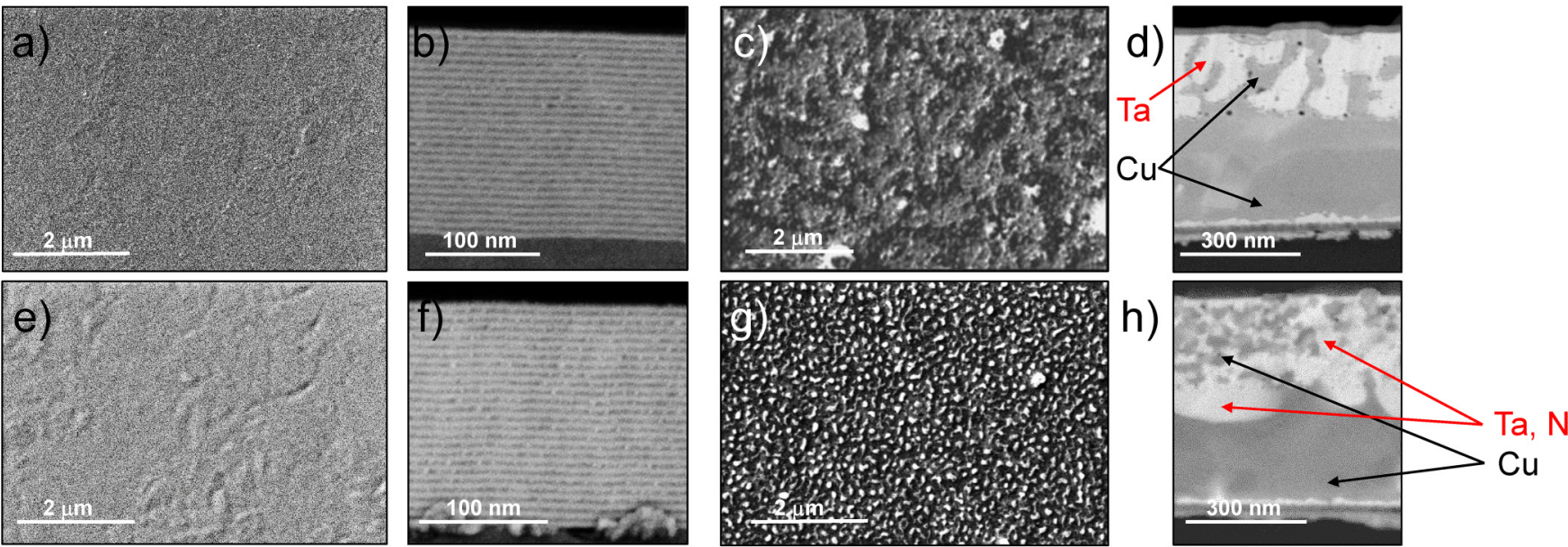

FIG. 2. Plan-view and cross-sectional SEM images of the as-deposited (a), (b), (e), and (f) and annealed (c), (d), (g), and (h) NMLs. Cu/Ta is displayed in (a)-(d), whereas Cu/TaN is displayed in (e)-(h). For these images, the NMLs consist of $5 \mathrm{~nm} / 5 \mathrm{~nm}$ layers repeated 25 times and correspondingly after annealing at $800{ }^{\circ} \mathrm{C}$.

considerably increased with respect to the as-deposited state, and the original stratified structure degrades into a nanocomposite structure, consisting of globular Ta and TaN agglomerates embedded in a Cu matrix [Figs. 2(d) and 2(h)]. The elemental composition of the different regions in 2(d) and 2(h) has been derived by energy dispersive $\mathrm{x}$-ray (EDX) analysis. The SEM analysis of $\mathrm{Cu} / \mathrm{W}$ NMLs before and after heat treatment has been extensively performed and reported in Refs. 21and 23. The NML to nanocomposite transformation was found to occur at $T>750^{\circ} \mathrm{C}$, resulting in the formation of NCs, consisting of $\mathrm{W}$ particles in a $\mathrm{Cu}$ matrix, and the microstructure of the degraded NML is found to depend strongly on the layer thickness and number of repetitions of the original nanolayers.

a)

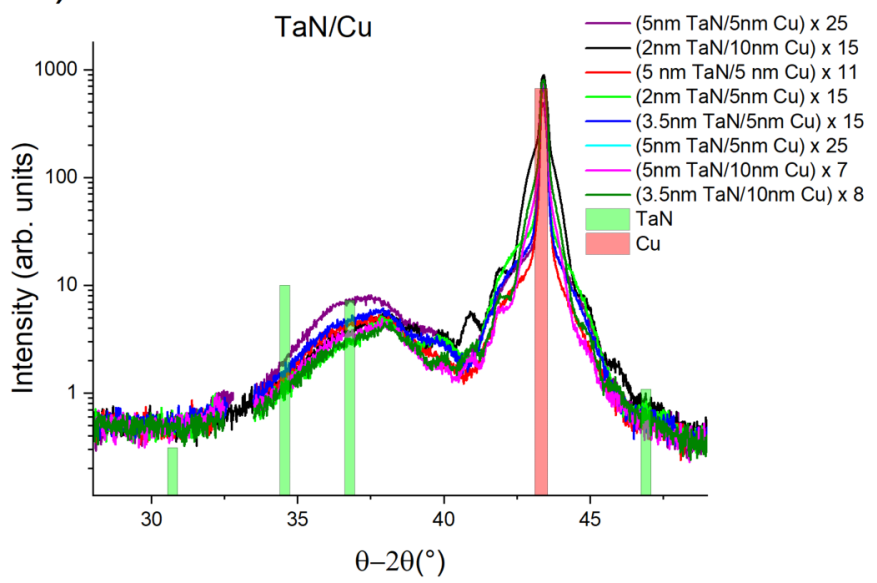

The XRD analysis of the as-deposited multilayers of $\mathrm{Cu} / \mathrm{Ta}$ is shown in Fig. 3. In Fig. S1 of the supplementary material, the XRD measurements of the single $\mathrm{Ta}$ and $\mathrm{Cu}$ layers are also presented. The $\mathrm{Cu}$ buffer layer is polycrystalline with a [111] texture, typical of $\mathrm{Cu}$ sputtered PVD films. ${ }^{49}$ The Ta layer grown on the $\mathrm{Cu}$ buffer layer is primarily composed of the $\beta$-Ta phases with a [001] preferential growth direction. The more common $\alpha$-Ta can hardly be distinguished in the as-deposited state and becomes evident only after annealing at $600^{\circ} \mathrm{C}$ (see the next paragraph). The $\mathrm{Cu} / \mathrm{Ta}$ multilayers present the typical intensity modulation of periodic superlattices; ${ }^{50}$ the oscillations are compatible with the $\beta$-Ta phase oriented along the [001] direction and the $\mathrm{Cu}$ layers oriented along [111], superimposed on the narrower $\mathrm{Cu}(111)$ peak from the buffer layer.

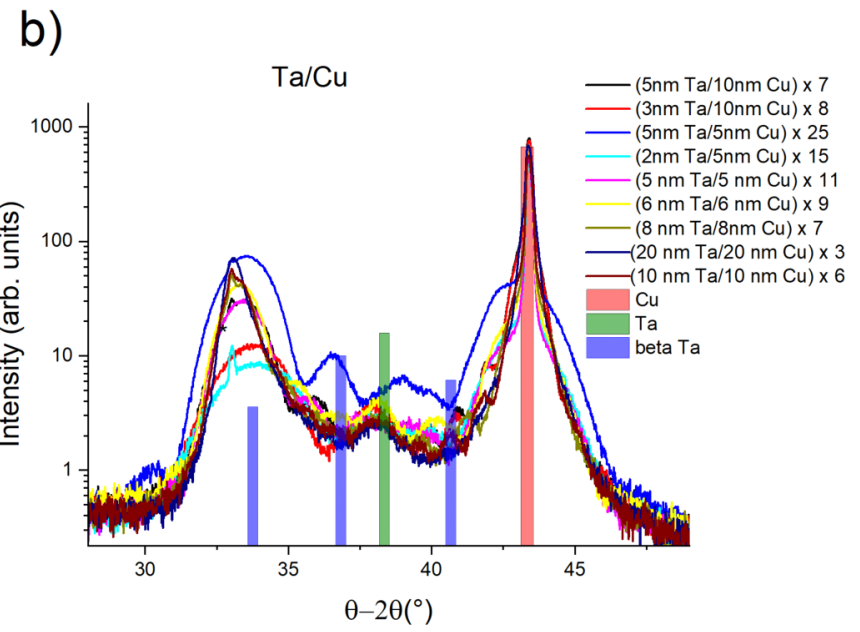

FIG. 3. XRD on the series of (a) $\mathrm{Cu} / \mathrm{Ta}$ and (b) $\mathrm{Cu} / \mathrm{TaN}$ NMLs with different thicknesses. The $\mathrm{Cu}$, Ta, and TaN references are also indicated. 
Similarly, the $\mathrm{Cu} / \mathrm{TaN}$ NMLs show preferential growth directions of [111] and [101] for the $\mathrm{Cu}$ and TaN layers, respectively. The as-deposited multilayers show similar XRD patterns independent of the layer thickness and period. No clear satellite peaks and pronounced finite size oscillations are observed, indicating a similar disorder and a defect concentration in the initial NML state. The TaN broad peak in the as-deposited scan [Fig. 4(d)] corresponds to the (101) Bragg reflection. The $\mathrm{Cu} / \mathrm{TaN}$ NMLs appear to be more disordered with broader and less intense peaks in the as-deposited state compared to $\mathrm{Cu} / \mathrm{Ta}$ NMLs. The pole figure in Fig. 4(a) confirms the polycrystallinity of $\mathrm{Cu}$ with a preferential [111] orientation with a fiber texture (rotational symmetry) in-plane. The $\beta$-Ta
$\{110\}$ pole figure also presents an in-plane fiber texture and 2 rings: one more pronounced at a tilt angle of $\sim 65^{\circ}$ and a lower intensity ring at $30^{\circ}$. The most intense ring corresponds to the angle between the $\{110\}$ planes and the [001] direction, confirming the preferential orientation of the Ta layers along [001]. The TaN pole figure in Fig. 4(b) confirms the disordered and partially amorphous nature of the TaN layer: only diffuse intensity is observed, and no poles or rings are observed at any tilt angles.

In Figs. 4(c) and 4(d), the structural evolution of the NMLs with temperature is reported. Up to an annealing temperature of $600^{\circ} \mathrm{C}$, no distinct structural changes are detected by XRD. Pronounced structural transformations are observed for both a)
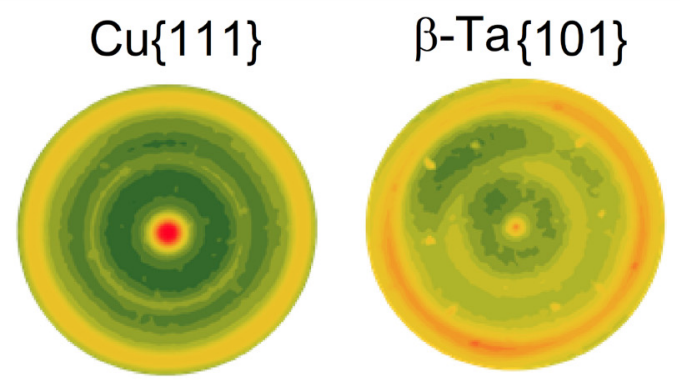

c)

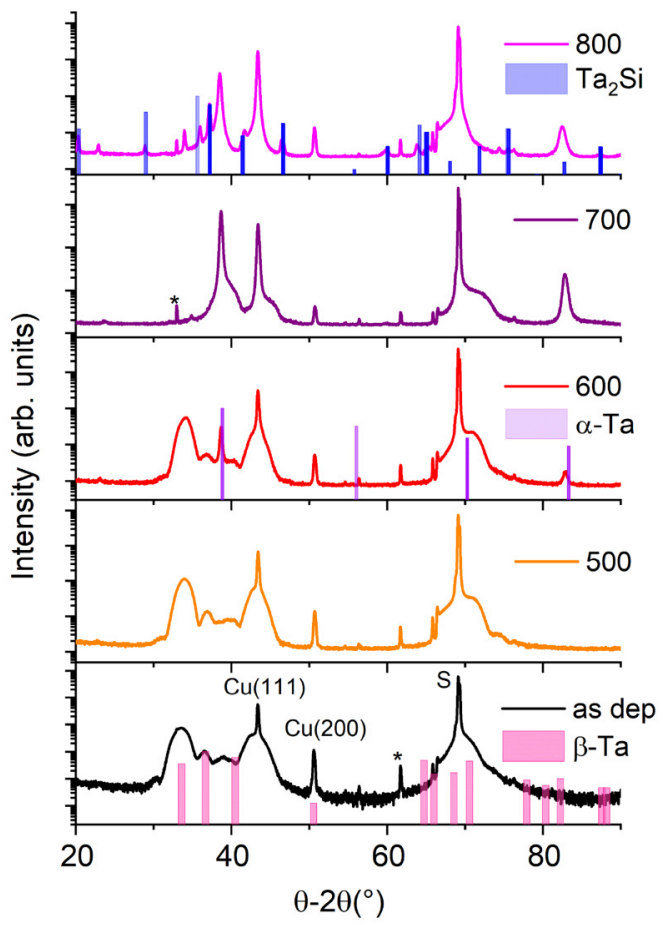

b)
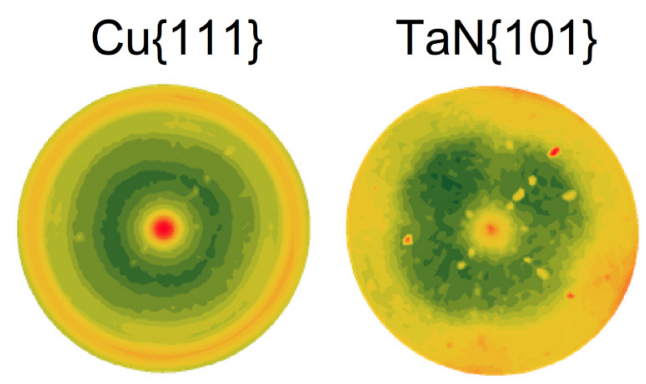

d)

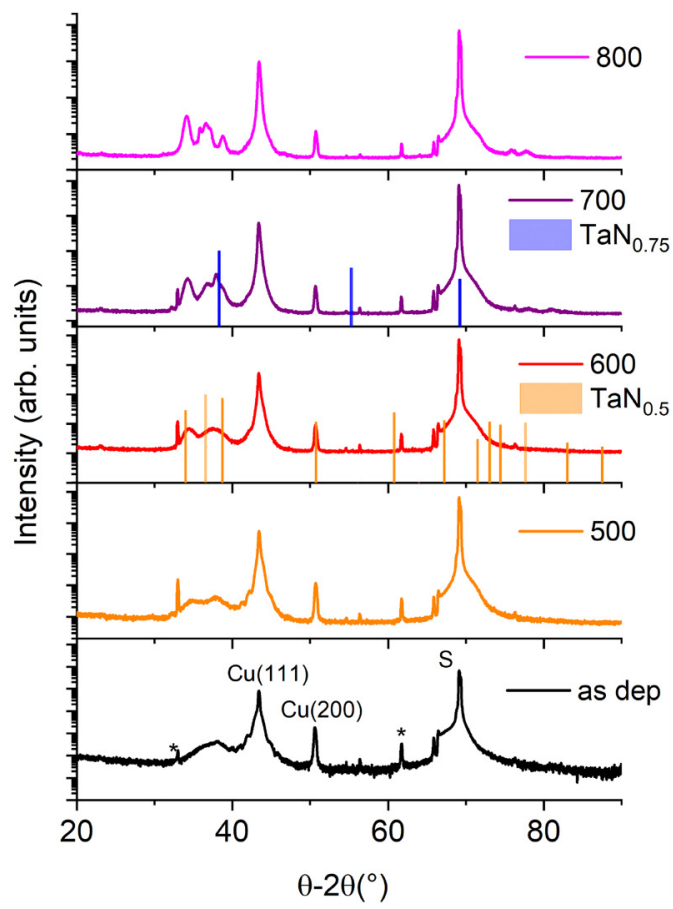

FIG. 4. (a) and (b) Pole figures of $\mathrm{Cu}\{111\}$ and Ta/TaN $\{101\}$ of $\mathrm{Cu} 5 \mathrm{~nm} / \mathrm{Ta} 5 \mathrm{~nm} \times 25$ and Cu10 nm/TaN3.5nm $\times 8$ in the as-deposited state. (c) and (d) are the XRD pattern of the $\mathrm{Cu} / \mathrm{Ta}$ and $\mathrm{Cu} / \mathrm{TaN}$ NMLs, respectively, collected in the as-deposited and after different annealing treatments. The reference bulk reflections of Ta, Ta $2 \mathrm{Si}$, Ta- $\beta$, and TaN are also indicated as they are observed. 
samples (i.e., $\mathrm{Ta}$ and $\mathrm{TaN}$ ), with and without $\mathrm{N}$, for annealing temperatures $\mathrm{T} \geq 700^{\circ} \mathrm{C}$. The $\beta$-Ta in $\mathrm{Cu} / \mathrm{Ta}$ NMLs transforms into an $\alpha$-Ta phase after annealing at $600^{\circ} \mathrm{C}$ [Fig. 4(c)]. Moreover, at $800^{\circ} \mathrm{C}$, the formation of Ta silicate phases is observed. On the contrary, no silicate phase formation is observed in $\mathrm{Cu} / \mathrm{TaN}$ NMLs after high-temperature annealing, demonstrating that $\mathrm{TaN}$ is a better Si diffusion barrier, which is in accordance with the literature $^{51,52}$ For the Cu/TaN NMLs, the TaN layers are polycrystalline and a sub-stoichiometric cubic phase develops during the annealing. In particular, the $\mathrm{TaN}_{0.5}$ phase is formed at $700^{\circ} \mathrm{C}$; additionally, at $800^{\circ} \mathrm{C}$, the $\mathrm{Ta}_{0.75} \mathrm{~N}$ phase is formed in coexistence with the $\mathrm{TaN}_{0.5}$ phase. In the $\mathrm{Cu} / \mathrm{W}$ NMLs, the periodic structure is preserved up to $700^{\circ} \mathrm{C}$, and for the individual layer thickness of $10 \mathrm{~nm}$, the multilayer structure is maintained up to $800^{\circ} \mathrm{C} .{ }^{21,23}$ If the $\mathrm{Cu}$ or $\mathrm{W}$ layer thickness is less than $10 \mathrm{~nm}$, the NML structure is completely destroyed after annealing at $T \geq 750^{\circ} \mathrm{C}$ and the system is transformed into NCs. In Sec. III B, we compare the thermal conductivity of all the annealed NMLs: after $800^{\circ} \mathrm{C}$ annealing, all the systems are completely transformed into NCs.

\section{B. Thermal conductivity and thermal boundary conductance}

The results of the TDTR measurements for the thermal conductivity of the multilayer regions are plotted in Fig. 5 as a function of the $\mathrm{Cu}$ thickness, the period thickness (the bilayer thickness of two adjacent films), and the interface density, which is defined as the number of film interfaces per nanometer within the transverse direction of the multilayer region. As $\mathrm{Cu}$ is the most thermally conductive material within the NML system, a general increase in thermal conductivity is observed with the increasing cumulative $\mathrm{Cu}$ layer thickness [Fig. 5(a)]. Correspondingly, the thermal conductivity increases in a similar manner as the total period thickness is increased [Fig. 5(b)].

For a given period thickness, trends in the measured thermal conductivity are closely coupled to the $\mathrm{Cu}$ concentration of a given period, which can explain the behavior of films that appear to be outliers of the general trend. For example, for the $\mathrm{Cu} / \mathrm{Ta}$ films, a large increase in the intrinsic thermal conductivity is observed in the $7 \mathrm{~nm}$ period case, which can be attributed to the fact that there is a $5 / 2 \mathrm{Cu} / \mathrm{Ta}$ ratio as opposed to a $1 / 1$ ratio in the other $\mathrm{Cu} / \mathrm{Ta}$ films. Similarly, for the $13.5 \mathrm{~nm}$ period $\mathrm{Cu} / \mathrm{TaN}$ sample, the increased thermal conductivity can be attributed to the $10 / 3.5 \mathrm{Cu} / \mathrm{TaN}$ ratio, which is a higher $\mathrm{Cu}$ concentration than in the other $\mathrm{Cu} / \mathrm{TaN}$ period thicknesses. Individual films thicknesses for each NML system are tabulated and provided in Table S3 of the supplementary material.

In contrast to the positive trends in Figs. 5(a) and 5(b), for the $\mathrm{Cu} / \mathrm{W}$ NMLs, as the interface density is increased, there is an observable reduction in the overall thermal conductivity of the multilayer region due to the cumulative thermal resistance of the interfaces [Fig. 5(c)]. To quantify the conductance of the interfaces, the thermal boundary conductance is calculated in the same manner as in Refs. 53 and 54, in which the resistances of the individual layers and corresponding interfaces within the multilayer region are assumed to add in series. The average thermal boundary conductance of the multilayer system, $G$, is then considered as the mean resistance between adjacent layers within a period according
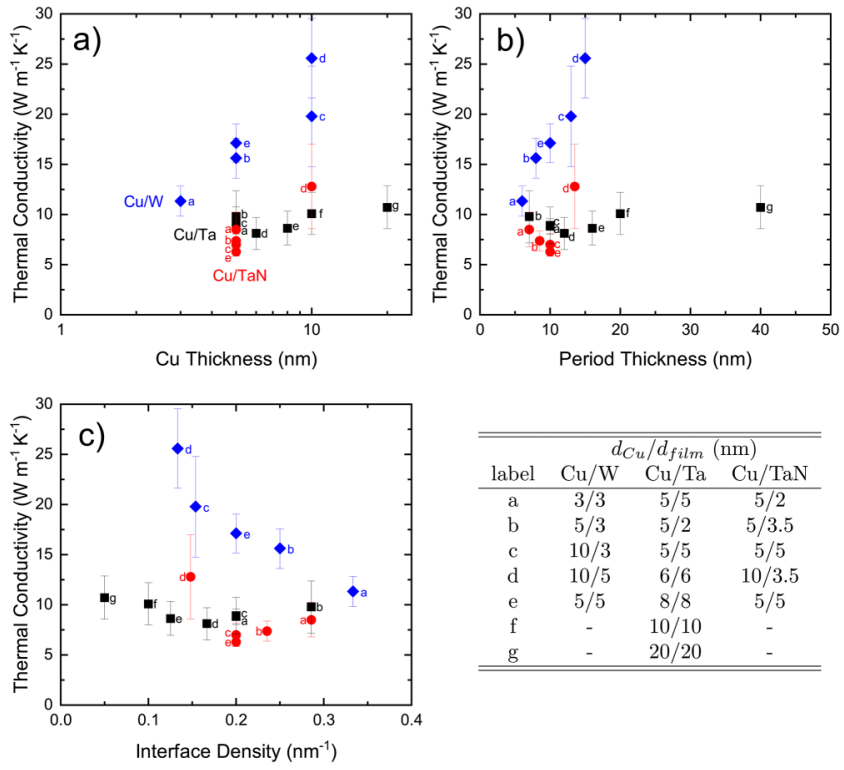

FIG. 5. Measured thermal conductivity of the NMLs as a function of (a) the $\mathrm{Cu}$ thickness (of a single period), (b) the period thickness, and (c) the interface density. The letters beside each data point are provided so that individual samples can be distinguished between each panel. For reference, the nominal period compositions are provided in the adjacent table. Complete details for each individual film are tabulated in Table S3 of the supplementary material.

to the equation

$$
G=2\left[\frac{d_{C u}+d_{f i l m}}{\kappa_{\text {measured }}}-\frac{d_{C u}}{\kappa_{C u}}-\frac{d_{f i l m}}{\kappa_{\text {film }}}\right]^{-1},
$$

where $\kappa_{\text {measured }}$ is the measured thermal conductivity of the multilayer region, $d_{C u}$ and $d_{\text {film }}$ are the thicknesses of adjacent layers, and $\kappa_{C u}$ and $\kappa_{\text {film }}$ are corresponding bulk copper and adjacent film thermal conductivities. We note that the subscript, film, in this notation is in reference to the film adjacent to $\mathrm{Cu}$ (in this case, $\mathrm{W}$ ). A series of films with different thicknesses of the respective pure metals were deposited on sapphire substrates to determine the bulk thermal conductivities of $\mathrm{Cu}$ and $\mathrm{W}$. The thermal conductivities of the thickest films $(600 \mathrm{~nm})$ were measured with TDTR and found to be 405 and $100 \mathrm{~W} \mathrm{~m}^{-1} \mathrm{~K}^{-1}$ for $\mathrm{Cu}$ and $\mathrm{W}$, respectively (see Fig. S8 in the supplementary material). Upon calculation of Eq. (1), the average TBC for all $\mathrm{Cu} / \mathrm{W}$ samples is found to be $3.9 \pm 0.4 \mathrm{GW} \mathrm{m}^{-2} \mathrm{~K}^{-1}$ and does not demonstrate an observable dependence upon the interface density. For reference, this derived value is within the range of other copper-metal interfaces calculated through a similar approach; for example, Cheaito et al. ${ }^{25}$ calculates the thermal boundary conductance between $\mathrm{Cu} / \mathrm{Nb}$ multilayers as $4.7 \mathrm{GW} \mathrm{m}^{-2} \mathrm{~K}^{-1}$, while Gundrum et al. ${ }^{26}$ find that of $\mathrm{Cu} / \mathrm{Al}$ to be 3.7 $\mathrm{GW} \mathrm{m}^{-2} \mathrm{~K}^{-1}$.

While a clear reduction in thermal conductivity is observed with increasing interface density for the $\mathrm{Cu} / \mathrm{W}$ NMLs, a negative 
trend in thermal conductivity is not observed for $\mathrm{Cu} / \mathrm{Ta}$ and $\mathrm{Cu} / \mathrm{TaN}$ NMLs, indicating that measurement of the multilayer systems is insensitive to the thermal boundary conductance; thus, calculation of the TBC via Eq. (1) would not be applicable.

For further insight into expected differences in the thermal boundary conductance between the different material interfaces, we consider values calculated from the electronic diffuse mismatch model (EDMM). This model assumes diffuse scattering of electrons at the interface and has been demonstrated as reasonably accurate at capturing trends in TBC even at low temperatures. ${ }^{25,26,55,56}$ Using the same analytical formalism outlined by Cheaito et al., ${ }^{25}$ the thermal boundary conductance at a metal/metal interface can be expressed as

$$
G_{1 / 2}=1 / 4 \zeta_{1 / 2} C_{e, 1} v_{F, 1}
$$

where $\zeta_{1 / 2}$ is the transmission coefficient from layer 1 to layer 2 and $C_{e, 1}$ and $v_{F, 1}$ are the electronic heat capacity and the Fermi velocity of layer 1 . The product of $1 / 4 C_{e, 1} \mathrm{v}_{F, 1}$ is also defined as the derivative of the electronic energy flux at the interface $\left(\partial q_{1} / \partial T\right)$. The electronic heat capacity of layer 1 is defined as $\pi^{2} / 3 D\left(E_{F, 1}\right) k_{B}^{2} T$, where $k_{B}$ is the Boltzmann constant and $D\left(E_{F, 1}\right)$ is the density of states at the Fermi energy of layer 1 . The transmission coefficient of the interface is then given as

$$
\zeta_{1 / 2}=\frac{D\left(E_{F, 2}\right) v_{F, 2}}{D\left(E_{F, 2}\right) v_{F, 2}+D\left(E_{F, 1}\right) v_{F, 1}} .
$$

Using these equations, we calculate the expected thermal boundary conductance for the elemental metals measured in this study (i.e., $\mathrm{Cu}, \mathrm{W}$, and $\mathrm{Ta}$ ) for which the Fermi energy, velocity, and density of states are well defined. For reference, we tabulate the necessary parameters for the transmission coefficient calculation in Table II. In all cases, the density of states at the Fermi energy as well as the Fermi velocity have been taken from literature. We note that in some cases, the Fermi velocity has been calculated from the Fermi energy, $E_{F}$, from the relation $v_{F}=\sqrt{2 E_{F} / m}$, where $m$ is the mass of an electron.

With these values, we calculate room-temperature thermal boundary conductances of 1.85 and $4.36 \mathrm{GW} \mathrm{m}^{-2} \mathrm{~K}^{-1}$ for $\mathrm{Cu} / \mathrm{Ta}$ and $\mathrm{Cu} / \mathrm{W}$, respectively. Despite the simplicity of this analytical

TABLE II. Resultant transmission coefficients and the thermal boundary conductance as calculated by the EDMM, outlined by Eqs. (2) and (3). For reference, the density of states and Fermi velocity values used in the calculations are also provided.

\begin{tabular}{lcc}
\hline \hline Metal & $D\left(E_{F}\right)\left(10^{47} \mathrm{~m}^{-3}\right)$ & $v_{F}\left(10^{6} \mathrm{~m} \mathrm{~s}^{-1}\right)$ \\
\hline $\mathrm{Cu}$ & $1.41^{25}$ & $1.12^{25}$ \\
$\mathrm{Ta}$ & $0.29^{57}$ & $1.83^{57}$ \\
$\mathrm{~W}$ & $1.63^{58}$ & $1.43^{59}$ \\
& & $\mathrm{G}_{1 / 2}\left(\mathrm{GW} \mathrm{m}^{-2} \mathrm{~K}^{-1}\right)$ \\
Interface $_{1 / 2}$ & $\zeta_{1 / 2}$ & 1.85 \\
$\mathrm{Cu} / \mathrm{Ta}$ & 0.25 & 4.36 \\
$\mathrm{Cu} / \mathrm{W}$ & 0.60 & \\
\hline \hline
\end{tabular}

model, there is a relatively good agreement with the experimentally determined $\mathrm{TBC}$ for $\mathrm{Cu} / \mathrm{W}$ (for example, $3.9 \pm 0.4$ as opposed to $4.36 \mathrm{GW} \mathrm{m}^{-2} \mathrm{~K}^{-1}$ for the experimentally determined and theoretical values, respectively).

While TBC has been shown to be closely correlated with the derivative of the electronic energy flux at the interface, ${ }^{25} \partial q_{1} / \partial T$ is the same as all metals are interfaced with copper. However, the transmission coefficient for $\mathrm{Cu} / \mathrm{W}$ is found to be higher than that of $\mathrm{Cu} / \mathrm{Ta}$, which is attributed to the higher density of states at the Fermi energy in $\mathrm{W}$ and thus gives rise to the higher overall TBC.

As an additional demonstration of the role of interfacial resistance on the thermal transport of the NMLs, we observe changes in the thermal conductivity as a function of the annealing temperature, displayed in Fig. 6. $\mathrm{Cu} / \mathrm{Ta}, \mathrm{Cu} / \mathrm{TaN}$, and $\mathrm{Cu} / \mathrm{W}$ samples with a nominal period thickness of $10 \mathrm{~nm}$ were each annealed at a constant temperature in the range of $500-800^{\circ} \mathrm{C}$. The total thicknesses of the multilayer regions were 238, 253.5, and $1000 \mathrm{~nm}$ for the $\mathrm{Cu} / \mathrm{Ta}, \mathrm{Cu} / \mathrm{TaN}$, and $\mathrm{Cu} / \mathrm{W}$ multilayers, respectively. No change in thermal conductivity is observed for the anneals below $600{ }^{\circ} \mathrm{C}$ as the multilayer stack retains the integrity of its layered structure as described in Sec. III A. However, while the NML structure does not degrade into a nanocomposite until annealing above $750{ }^{\circ} \mathrm{C}$, recent works have demonstrated that subtle interface alterations occur at lower temperatures, which can subsequently impact carrier transport. For example, in a study by Powers et al., ${ }^{16}$ it has been demonstrated that for anneals below $400^{\circ} \mathrm{C}$, interfaces within $\mathrm{Cu} / \mathrm{Ta}$ NMLs retain a flat surface, while for temperatures above $600{ }^{\circ} \mathrm{C}$,

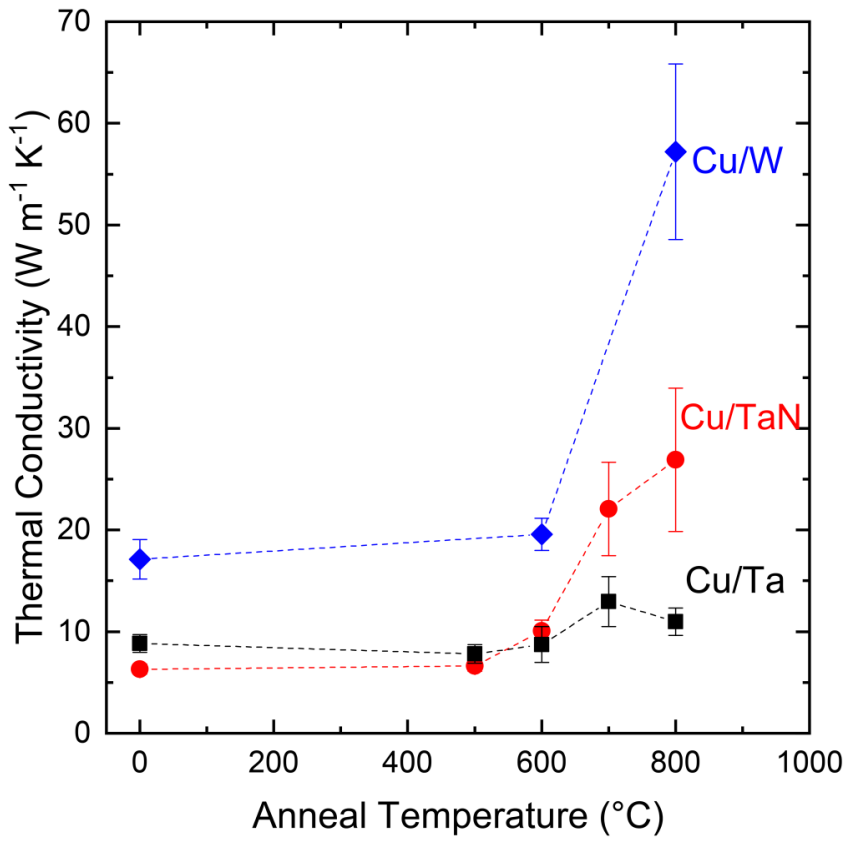

FIG. 6. Thermal conductivity of the $\mathrm{Cu} / \mathrm{Ta}, \mathrm{Cu} / \mathrm{TaN}$, and $\mathrm{Cu} / \mathrm{W}$ multilayer regions as a function of anneal temperature. Prior to the anneal, the period thickness for each multilayer system was $10 \mathrm{~nm}$, whereas the total multilayer thickness of the layer is $238,253.5$, and $1000 \mathrm{~nm}$ for $\mathrm{Cu} / \mathrm{Ta}, \mathrm{Cu} / \mathrm{TaN}$, and $\mathrm{Cu} / \mathrm{W}$, respectively. 
hillock formations have been observed. Furthermore, the NMLs within the figure are composed of $10 \mathrm{~nm}$ periods; in another recent work on $\mathrm{Cu} / \mathrm{W}$ multilayer systems, Dong et al. have demonstrated that in systems with layers less than $12 \mathrm{~nm}$, phonon transport also plays a non-negligible role. In the case of phonon transport, interfacial resistance is inherently linked to the overlap of phonon states between two adjacent materials; therefore, any intermixing of adjacent materials at the interface could have an averaging effect on the vibrational spectra, ${ }^{60-63}$ thereby reducing the interfacial resistance and increasing the measured thermal conductivity.

Outside of reductions in the interfacial resistance, increases in the thermal conductivity at temperatures $\leq 700^{\circ} \mathrm{C}$ could be correlated to the formation of lower resistivity phases. For example, XRD measurements of the annealed films demonstrate the formation of $\alpha$-Ta by $600{ }^{\circ} \mathrm{C}$ in the $\mathrm{Cu} / \mathrm{Ta}$ multilayers [Fig. 4(c)] and $\mathrm{TaN}_{0.5}$ in the $\mathrm{Cu} / \mathrm{Ta}$ at $700{ }^{\circ} \mathrm{C}$ [Fig. $\left.4(\mathrm{~d})\right]$. The film resistivity can, in some cases, be reduced by an order of magnitude or more, such as in the case of $\beta$-Ta to $\alpha$-Ta as discussed by Wang et al. ${ }^{64}$ and Grosser and Schmid ${ }^{65}$ and investigated through first-principles calculations by Lanzillo et al. ${ }^{10}$ As the electronic contribution to thermal conductivity is inversely proportional to the electrical resistivity through the Wiedemann-Franz law, a corresponding increase in thermal conductivity would be expected with the onset of these lower resistivity phases.

Once the annealing temperature approaches $800^{\circ} \mathrm{C}$, the layered structure of the multilayer region is lost as there is significant diffusion between the $\mathrm{Cu}$ and $\mathrm{W}, \mathrm{Ta}$, or TaN films. As such, there is a reduction in the interface density of the region, and the thermal conductivity is enhanced. While all samples display an increase in thermal conductivity as a function of the annealing temperature, a slight decrease is observed for the $\mathrm{Cu} / \mathrm{Ta} \mathrm{NML}$ annealed at $800^{\circ} \mathrm{C}$. As previously discussed in the XRD results, at $800^{\circ} \mathrm{C}$, the formation of Ta silicate phases is observed, indicating $\mathrm{Si}$ diffusion from the substrate into the NML region. The presence of Ta silicate in the region could prove as a source of alloy scattering and could consequently be responsible for the reduction in measured thermal conductivity.

\section{CONCLUSION}

In summary, a comprehensive comparison has been prepared for $\mathrm{Cu}$-based nanomultilayers. NMLs were grown over a range of layer and period thicknesses for films of $\mathrm{Cu} / \mathrm{Ta}, \mathrm{Cu} / \mathrm{TaN}$, and $\mathrm{Cu} / \mathrm{W}$, and the thermal and structural properties of the films were characterized through TDTR, SEM, and XRD measurements. For further insight into the role of the NML structure upon thermal transport, samples were annealed to the point of layer diffusion, yielding significant increases in the measured thermal conductivity, demonstrating the critical role of interfacial resistance on thermal transport within these systems.

\section{SUPPLEMENTARY MATERIAL}

See the supplementary material for additional details on XRD, AFM, sheet resistance measurements, sensitivity analyses of the measured thermal properties as well as tabulated values of the thermophysical properties of the samples in this study.

\section{AUTHORS' CONTRIBUTIONS}

C.C. and E.A.S. contributed equally to this work.

\section{ACKNOWLEDGMENTS}

The authors are thankful to Dr. H. R. Elsener for his help on performing thermal treatments. We appreciate support from the Army Research Office through a MURI program, Award No. W911NF-16-1-0406.

\section{DATA AVAILABILITY}

The data that support the findings of this study are available from the corresponding author upon reasonable request.

\section{REFERENCES}

${ }^{1}$ D. Gall, J. Appl. Phys. 127, 050901 (2020).

${ }^{2}$ R. S. Smith, E. T. Ryan, C.-K. Hu, K. Motoyama, N. Lanzillo, D. Metzler, L. Jiang, J. Demarest, R. Quon, L. Gignac, C. Breslin, A. Giannetta, and S. Wright, AIP Adv. 9, 025015 (2019).

${ }^{3}$ D. Valencia, E. Wilson, Z. Jiang, G. A. Valencia-Zapata, K.-C. Wang, G. Klimeck, and M. Povolotskyi, Phys. Rev. Appl. 9, 044005 (2018).

${ }^{4}$ N. A. Lanzillo, O. D. Restrepo, P. S. Bhosale, E. Cruz-Silva, C.-C. Yang, B. Youp Kim, T. Spooner, T. Standaert, C. Child, G. Bonilla, and K. V. R. M. Murali, Appl. Phys. Lett. 112, 163107 (2018).

${ }^{5}$ N. A. Lanzillo, J. Appl. Phys. 121, 175104 (2017).

${ }^{6}$ S. M. Merchant, S. H. Kang, M. Sanganeria, B. van Schravendijk, and T. Mountsier, JOM 53, 43 (2001).

${ }^{7}$ J. Kriz, C. Angelkort, M. Czekalla, S. Huth, D. Meinhold, A. Pohl, S. Schulte, A. Thamm, and S. Wallace, Microelectron. Eng. 85, 2128 (2008).

${ }^{8}$ M. W. Lane, C. E. Murray, F. R. McFeely, P. M. Vereecken, and R. Rosenberg, Appl. Phys. Lett. 83, 2330 (2003).

${ }^{9} \mathrm{M}$. Wislicenus, R. Liske, L. Gerlich, B. Vasilev, and A. Preusse, Microelectron. Eng. 137, 11 (2015).

${ }^{10}$ N. A. Lanzillo, L. Clevenger, R. R. Robison, and D. C. Edelstein, J. Appl. Phys. 127, 125705 (2020).

${ }^{11}$ L. P. Jeurgens, Z. Wang, and E. J. Mittemeijer, Int. J. Mater. Res. 100, 1281 (2009).

12 F. Spaepen, Acta Mater. 48, 31 (2000).

${ }^{13} \mathrm{~T}$. W. Barbee, in Symposium V-Application of Synchrotron Radiation Techniques...IV, MRS Proceedings (Materials Research Society, 1998), Vol. 524, p. 145.

${ }^{14}$ J. Xue, Y. Li, L. Gao, D. Qian, Z. Song, X. Wang, X. Zhu, and J. Chen, Surf. Coat. Technol. 381, 125179 (2020).

${ }^{15}$ L. Dong, G. Wei, T. Cheng, J. Tang, X. Ye, M. Hong, L. Hu, R. Yin, S. Zhao, G. Cai, Y. Shi, B. Pan, C. Jiang, and F. Ren, ACS Appl. Mater. Interfaces 12, 8886 (2020).

${ }^{\mathbf{1 6}}$ M. Powers, B. Derby, E. Raeker, N. Champion, and A. Misra, Thin Solid Films 693, 137692 (2020).

${ }^{17}$ A. Giri and P. E. Hopkins, Adv. Funct. Mater. 30, 1903857 (2020).

${ }^{18}$ T. Zhan, K. Oda, S. Ma, M. Tomita, Z. Jin, H. Takezawa, K. Mesaki, Y.-J. Wu, Y. Xu, T. Matsukawa, T. Matsuki, and T. Watanabe, ACS Appl. Mater. Interfaces 12, 22347 (2020).

${ }^{19}$ A. Every, Y. Tzou, D. Hasselman, and R. Raj, Acta Metall. Mater. 40, 123 (1992).

${ }^{20}$ C.-W. Nan, R. Birringer, D. R. Clarke, and H. Gleiter, J. Appl. Phys. 81, 6692 (1997).

${ }^{21}$ F. Moszner, C. Cancellieri, M. Chiodi, S. Yoon, D. Ariosa, J. Janczak-Rusch, and L. P. H. Jeurgens, Acta Mater. 107, 345 (2016).

${ }^{22}$ C. Cancellieri, F. Moszner, M. Chiodi, S. Yoon, J. Janczak-Rusch, and L. P. H. Jeurgens, J. Appl. Phys. 120, 195107 (2016). 
${ }^{23}$ A. V. Druzhinin, D. Ariosa, S. Siol, N. Ott, B. B. Straumal, J. Janczak-Rusch, L. P. H. Jeurgens, and C. Cancellieri, Materialia 7, 100400 (2019).

${ }^{24}$ H.-J. Lee, K.-W. Kwon, C. Ryu, and R. Sinclair, Acta Mater. 47, 3965 (1999).

${ }^{25}$ R. Cheaito, K. Hattar, J. T. Gaskins, A. K. Yadav, J. C. Duda, T. E. Beechem, J. F. Ihlefeld, E. S. Piekos, J. K. Baldwin, A. Misra, and P. E. Hopkins, Appl. Phys. Lett. 106, 093114 (2015).

${ }^{26}$ B. C. Gundrum, D. G. Cahill, and R. S. Averback, Phys. Rev. B: Condens. Matter Mater. Phys. 72, 245426 (2005).

${ }^{27}$ P. E. Hopkins, T. E. Beechem, J. C. Duda, J. L. Smoyer, and P. M. Norris, Appl. Phys. Lett. 96, 011907 (2010).

28 B. M. Clemens, G. L. Eesley, and C. A. Paddock, Phys. Rev. B 37, 1085 (1988).

${ }^{29}$ S. W. King, M. French, M. Jaehnig, M. Kuhn, B. Boyanov, and B. French, J. Vac. Sci. Technol. B 29, 051207 (2011).

${ }^{30} \mathrm{~A}$. Schmidt, "Optical characterization of thermal transport from the nanoscale to the macroscale," Ph.D. dissertation (Massachusetts Institute of Technology, 2008).

${ }^{31}$ D. G. Cahill, Rev. Sci. Instrum. 75, 5119 (2004).

${ }^{32}$ D. G. Cahill, K. E. Goodson, and A. Majumdar, J. Heat Transfer 124, 223 (2002).

${ }^{33}$ P. E. Hopkins, J. R. Serrano, L. M. Phinney, S. P. Kearney, T. W. Grasser, and C. T. Harris, J. Heat Transfer 132, 081302 (2010).

${ }^{34} \mathrm{Y}$. Touloukian and E. Buyco, in Thermophysical Properties of Matter-Specific Heat: Nonmetallic Solids, edited by Y. Touloukian and C. Ho (IFI/Plenum, New York, 1970), Vol. 5.

${ }^{35}$ A. Sood, R. Cheaito, T. Bai, H. Kwon, Y. Wang, C. Li, L. Yates, T. Bougher, S. Graham, M. Asheghi, M. Goorsky, and K. E. Goodson, Nano Lett. 18, 3466 (2018).

${ }^{36}$ E. A. Scott, S. W. Smith, M. D. Henry, C. M. Rost, A. Giri, J. T. Gaskins, S. S. Fields, S. T. Jaszewski, J. F. Ihlefeld, and P. E. Hopkins, Appl. Phys. Lett. 113, 192901 (2018).

${ }^{37}$ P. E. Hopkins, L. M. Phinney, J. R. Serrano, and T. E. Beechem, Phys. Rev. B: Condens. Matter Mater. Phys. 82, 085307 (2010).

${ }^{38}$ W. F. Giauque and P. F. Meads, J. Am. Chem. Soc. 63, 1897 (1941).

${ }^{39} \mathrm{P}$. Nath and K. Chopra, Thin Solid Films 20, 53 (1974).

${ }^{40} \mathrm{~A}$. Tesfamicha and A. D. Woldeyo, Asian J. Sci. Res. 6, 339 (2013).

${ }^{41}$ J. Bryner, D. M. Profunser, J. Vollmann, E. Mueller, and J. Dual, Ultrasonics 44, e1269 (2006).

${ }^{42}$ E. Bozorg-Grayeli, Z. Li, M. Asheghi, G. Delgado, A. Pokrovsky, M. Panzer, D. Wack, and K. E. Goodson, Appl. Phys. Lett. 99, 261906 (2011).

${ }^{43}$ C. H. Mastrangelo, T. Yu-Chong, and R. S. Muller, Sens. Actuators A 23, 856 (1990).
${ }^{44}$ J. T. Gaskins, P. E. Hopkins, D. R. Merrill, S. R. Bauers, E. Hadland, D. C. Johnson, D. Koh, J. H. Yum, S. Banerjee, B. J. Nordell, M. M. Paquette, A. N. Caruso, W. A. Lanford, P. Henry, L. Ross, H. Li, L. Li, M. French, A. M. Rudolph, and S. W. King, ECS J. Solid State Sci. Technol. 6, N189 (2017).

${ }^{\mathbf{4 5}}$ N. Stojanovic, J. Yun, J. M. Berg, M. Holtz, and H. Temkin, in ASME 2007 International Mechanical Engineering Congress and Exposition, 11-15 November 2007, Seattle, Washington (ASME, 2009), Vol. 26, pp. 639-645.

${ }^{46}$ J. L. Braun, D. H. Olson, J. T. Gaskins, and P. E. Hopkins, Rev. Sci. Instrum. 90, 024905 (2019).

${ }^{\mathbf{4 7}}$ G. White and S. Collocott, J. Phys. Chem. Ref. Data 13, 1251 (1984).

${ }^{48}$ J. Hostetler, A. Smith, and P. Norris, Microscale Thermophys. Eng. 1, 237 (1997).

${ }^{49}$ C. Thompson, Acta Metall. 36, 2929 (1988).

${ }^{50}$ B. M. Clemens and J. G. Gay, Phys. Rev. B 35, 9337 (1987).

${ }^{51}$ K. Holloway, P. M. Fryer, C. Cabral, J. M. E. Harper, P. J. Bailey, and K. H. Kelleher, J. Appl. Phys. 71, 5433 (1992).

${ }^{52}$ R. Hübner, M. Hecker, N. Mattern, V. Hoffmann, K. Wetzig, C. Wenger, H.-J. Engelmann, C. Wenzel, E. Zschech, and J. Bartha, Thin Solid Films 437, 248 (2003).

${ }^{53}$ Y. K. Koh, Y. Cao, D. G. Cahill, and D. Jena, Adv. Funct. Mater. 19, 610 (2009).

${ }^{54}$ A. Giri, S. W. King, W. A. Lanford, A. B. Mei, D. Merrill, L. Li, R. Oviedo, J. Richards, D. H. Olson, J. L. Braun, J. T. Gaskins, F. Deangelis, A. Henry, and P. E. Hopkins, Adv. Mater. 30, 1804097 (2018).

${ }^{55}$ R. B. Wilson and D. G. Cahill, Phys. Rev. Lett. 108, 255901 (2012).

${ }^{56}$ C. B. Saltonstall, Z. D. McClure, M. J. Abere, D. Guzman, S. T. Reeve, A. Strachan, P. G. Kotula, D. P. Adams, and T. E. Beechem, Phys. Rev. B 101, $245422(2020)$.

${ }^{57}$ L. F. Mattheiss, Phys. Rev. B 1, 373 (1970).

${ }^{58}$ Z. Lin, L. V. Zhigilei, and V. Celli, Phys. Rev. B 77, 075133 (2008).

${ }^{59}$ M. S. Sodha and P. K. Dubey, J. Phys. D: Appl. Phys. 3, 139 (1970).

${ }^{60}$ R. J. Stevens, L. V. Zhigilei, and P. M. Norris, Int. J. Heat Mass Transfer 50, 3977 (2007).

${ }^{61}$ Z. Liang and H.-L. Tsai, J. Phys.: Condens. Matter 23, 495303 (2011).

${ }^{62}$ T. S. English, J. C. Duda, J. L. Smoyer, D. A. Jordan, P. M. Norris, and L. V. Zhigilei, Phys. Rev. B 85, 035438 (2012).

${ }^{63}$ Z. Tian, K. Esfarjani, and G. Chen, Phys. Rev. B 86, 235304 (2012).

${ }^{64}$ W.-L. Wang, W.-C. Chen, K.-T. Peng, H.-C. Kuo, M.-H. Yeh, H.-J. Chien, and T.-H. Ying, Thin Solid Films 603, 34 (2016).

${ }^{65} \mathrm{M}$. Grosser and U. Schmid, Thin Solid Films 517, 4493 (2009). 